DOI: https://doi.org/10.47405/mjssh.v6i10.1078

\begin{tabular}{|c|c|}
\hline$y_{x=1}$ & Malaysian Journal of Social Sciences and Humanities (MJSSH) \\
\hline $\begin{array}{l}\text { Malaysian Journal of } \\
\text { Socrai scciecces and }\end{array}$ & Volume 6, Issue 10, October 2021 \\
\hline (MJ-SSH) & e-ISSN : 2504-8562 \\
\hline & $\begin{array}{l}\text { Journal home page: } \\
\text { www.msocialsciences.com }\end{array}$ \\
\hline
\end{tabular}

\title{
Legal Challenges of the Covid-19 Vaccination Program: A Comparative Discourse between Malaysia and Australia
}

\author{
Norazlina Abdul Aziz ${ }^{1}$, Mastika Nasrun' ${ }^{1}$, Nurasma Yahaya ${ }^{1}$, Sarah Munirah Abdullah ${ }^{1}$ \\ ${ }^{1}$ Faculty of Law, Universiti Teknologi MARA, Selangor, Malaysia \\ Correspondence: Mastika Nasrun (mastika@uitm.edu.my)
}

\begin{abstract}
During the spread of the COVID-19 pandemic, many health-related industries were alarmed and pressured to innovate solutional vaccines to reduce the effect of the COVID-19 pandemic. Extra effort and lab activities had taken place in several jurisdictions to respond to the increased demand for the COVID-19 vaccine. With these attempts, various vaccines were created and entered the market. All countries designed their own COVID-19 programme in the route to combat the viruses. These countries showed their willingness to invest to secure access to vaccines. In parallel to this development, the vaccination program is bombarded with several issues such as safety assurance, equal access to the vaccine, and protests by the anti-vaccine group. The inability to address these issues will jeopardise the success of building herd immunity which is the core in eradicating COVID-19 cases. Thus, this study explored and analysed the issues and challenges to have an effective vaccination program in a battle against the spread of the COVID-19 virus. It is a comparative study between Malaysia and Australia that includes safety measures, anti-vaccine groups and access to vaccines. This study adopts a qualitative method utilising the doctrinal study on the legal framework that describes the scope and limitation of power accorded to the Drug Control Authority of the selected jurisdictions. The research activities also include semi-structured interviews with relevant authorities using online interviews. The data are analysed using content and thematic analysis. Findings to this study may assist in identifying the loopholes within the administrative control on the vaccination program adopted by Malaysia.
\end{abstract}

Keywords: vaccine, COVID-19, Malaysia, drug control authority, law

\section{Introduction}

COVID-19 vaccine has been regarded as one of the well-received options to manage the global pandemic. Tainted with negative perceptions of its safety and efficacy, especially during its early phase, it is crucial to alleviate the public concern and vaccine hesitancy group. In their articles, Borriello et al. (2021) disclosed that concerns regarding vaccine safety are indeed a significant component in the surge of vaccine hesitancy. It is especially true in the present COVID-19 pandemic, where vaccines are being developed at a rapid pace. The public concerns on safety affirmations of vaccine products (Bernama, 2021; Wan Abhar, 2021) were instigated by the widely spread information on the adverse effect of vaccination. The queries regarding the safety of vaccines are related to speculation on the insufficient period of efficacy testing (Kaur et al., 2021) the unestablished report on the adverse reaction towards the newly invented vaccine, the active components in the vaccine, and the halal status of the vaccine (Khoo et al., 2020). The arrival and distribution of safe, effective COVID-19 
vaccines are the significant development in the coronavirus pandemic. As more people are vaccinated, families and communities will be able to gradually return to a more normal routine (Lisa \& David Kelen, 2021). Responding to the demand for safety assurance of the vaccine products, pharmaceutical control authorities of all countries experienced the increased burden in finding and innovating solutional vaccines to curb the spread of the COVID-19 virus and assure the safety of the people. Developing pharmaceuticals usually requires a more extended testing period to ensure the safety, efficacy, and quality aspects of the newly invented drug and the vaccine. This study investigates the power and role of the Pharmaceutical Control Authority of Malaysia and Australia to consolidate the best practice adopted by these jurisdictions. The findings assist in formulating recommendations for appropriate legal measures to control the safety and efficacy of vaccines during the crisis. The study adopts a qualitative research methodology utilising doctrinal study and semi-structured interviews. The data acquired through doctrinal research and semi-structured interview are integrated and analysed using content and thematic analysis.

\section{Literature Review}

Immunisation has long been introduced to address the issue of fatal infectious diseases caused by pandemics or epidemics (Joslyn Panting et al., 2018; Wong \& Lee, 2021). History recorded that at every spread of a pandemic, the healthcare practitioners, researchers, and policymakers around the globe were thrown a challenge to deliver adequate prevention and treatment modalities to combat the pandemic (Kaur et al., 2021; Kashte et al., 2021; Deplanque \& Launay, 2021). Much research was carried out on this area covering related issues like the development of vaccines (Mukherjee, 2020), the emergence of the vaccine-hesitant group, the impact of non-vaccinated children on the future population, the adverse impact of vaccination (Mukherjee, 2020), and innovation of new vaccine (Lisa \& David Kelen, 2021). Studies in other countries have documented various factors affecting parents' decision to vaccinate their children Khoo et al. (2020).

The writings (Wan Taib et al., 2017; Joslyn Panting et al., 2018; Silva et al., 2021) on the emergence of hesitant vaccine groups agree that the attitude and behaviour of the followers of the hesitant group do have a future impact on the society. The tendency of epidemic or pandemic revival is one of the future impacts (Joslyn Panting et al., 2018). The root of the rejection of vaccine uptake provides material information for the government planning to achieve herd immunity (Silva et al., 2021) and eradicate the pandemic. Concerning this, a study by Rumetta et al. (2020) highlighted that vaccine-related diseases are increasing in developing countries. Both Rumetta et al. (2020) and Joslyn Panting et al., (2018) used an attitude-based model to identify the causes of the targeted group hesitancy act. Under these studies, doubting the halal status of the vaccine was not one of the factors identified.

Although these articles contributed to explaining Malaysian acceptance behaviour towards vaccination, it has not addressed the importance of determining the vaccine's halal status. However, the review made by Khoo et al., (2020) consolidated the unique considerations for manufacturing and the regulation of new vaccines in Muslim-populated countries such as Malaysia. On the area of vaccine's safety and efficacy, to date, there is no comprehensive review of safety data reported from the vaccine trials, which forms a piece of critical information for the policymaker to improve uptake of COVID-19 vaccines and mitigate the risk aversion perceived due to the COVID-19 vaccine side effects (Kaur et al., 2021; Kashte et al., 2021; Deplanque \& Launay, 2021). In a report, (The Secretariat of the Special Committee for Ensuring Access to Covid-19 Supply (JKJAV), 2021) it was said that in negotiations for the purchase of the COVID-19 vaccine, the Malaysian government has included value-added elements to enable Malaysia to develop our vaccine development capacity in the country (Ramli et al., 2020). Although this study had researched the procedures to create a permissible vaccine, an in-depth discussion on the role of the Drug Control Authority was absent.

Another area explored by previous authors is the right to vaccine access. Sharun \& Dhama, (2021) discussed the importance of equal access to the COVID-19 vaccine, responding to the latest COVID19 vaccine products that were excessively conquered by the developed countries to the detriment of insufficient vaccines for developing countries. On a similar issue, Kuok \& Wong (2021) wrote on the 
vaccine administration and immunisation plans that are unveiled every day and how the authorities have also been quick to issue warnings on "queue jumping". Based on the precedent literature, it can be summarised that although much research has been carried out on the COVID-19 vaccine, an in-depth comparative discussion on the role of Drug Control Authorities of different world countries has not been carried out.

\section{Methodology}

This research employed a qualitative approach. The methods involved the collection, analysis, and integration of various sources of qualitative data. The researchers used the literature review to generate a specific set of theories and later integrated and corroborated the generated ideas through semistructured interviews.

\section{Phase 1 Literature Review}

i. Critically reviewed all literature on the concept and issues relating to vaccines together with their monitoring/control measures from various sources including textbooks, journal articles, government reports, newspaper articles, and online sources.

ii. Critically reviewed the role and power of the Drug Control Authorities in Australia and Malaysia to identify best practices that can be adopted to improve the existing role and power of the Malaysian Drug Control Authority in monitoring the COVID-19 vaccine.

\section{Phase 2 Data Collection}

i. A preliminary study was conducted to ensure the trustworthiness of the interview protocols and checklist.

ii. The procedures of the qualitative data collection included examination of documents and semistructured interviews. The respondents were chosen based on a purposive sampling technique and based on their occupational roles. The semi-structured interviews involved the analysis of administrative records and reports.

iii. For triangulation with the above-mentioned collected data, the primary data from semistructured interviews were combined with the preliminary findings gathered through analysis of documents.

\section{Phase 3 Data Analysis}

i. The grounded theory approach was adopted to analyse the qualitative data through thematic and content analyses, in which the interview transcripts were analysed. The process consisted of creating codes and categories, gleaning themes about the respondents' experiences. Also, such data were integrated with the experts' opinions on the issues and the literature review.

ii. The data analysis was conducted using qualitative software, ATLAS.ti version 9.

iii. The results obtained from the primary and secondary data from the findings of the research that were inserted in this writing

\section{Result}

The findings of this study uncover some similar challenges faced by the Malaysian and Australian governments in monitoring and controlling the safety and efficacy of COVID-19 vaccines. The findings are summarised in the following table that entails the key comparative points, including the safety assurance mechanism such as the clinical trial reliability, registration, and powers of the drug control authority. Other than monitoring the safety and efficacy aspects, the study also explores the 
pertinent issues attached to both jurisdictions' national COVID-19 vaccination program. Issues like the vaccine-hesitant group and adequate access to global vaccines are seen as threats to the government's effort in combating the COVID-19 pandemic.

Table 1: Comparative Analysis between Malaysia \& Australia

\section{The Drug Control Authority}

Usage approval/ Safety Efficacy check

National Pharmaceutical
Regulatory Agency (NPRA)

National
Regulatory Agency (NPRA)

\section{Therapeutic}

Administration (TGA)

TGA controls products that are listed as therapeutic goods including vaccines, at the federal level

The provisional approval pathway (PAP). TGA will run checks on every batch of the vaccines.

The NPRA's evaluation is based on international regulatory norms and procedures.

Non-applicable for production of vaccines as Malaysia is a nonproducer of vaccines.

$$
\text { procedures. }
$$

Malaysia is a non-producer of the COVID-19 vaccine product.

\section{Registration of vaccine}

\section{Import of vaccine}

COVID-19 vaccines in an ongoing Phase III clinical study or those authorised to use by any other DCA or WHO are eligible for conditional registration.

Only local distribution companies can submit a drug-based product registration application.

Therefore, foreign companies with no local presence in Malaysia must use a Marketing Authorization Holder (MAH) as their local representative.

MAH is responsible for the product application, as well as the quality, safety, and efficacy of the product (Regulation 7(1)(a), CDCR, 1984)
PAP is valid for an initial duration of two years, entitling the pharmaceutical companies to supply the vaccines to Australian populations legally.

This period could be further extended for up to two extensions amounting to a maximum of six years upon the application of the pharmaceutical companies.

Overlapping method where the usual process is the phase-byphase process.

The initial regulatory approval for the use of COVID-19 vaccines through the provisional determination and registration pathway

Australia manufactures some of the vaccines.

TGA provisionally registers the vaccine for imported vaccines before the vaccine is imported into Australia, subject to strict import requirements.

The quality of every batch of vaccine is tested before it is supplied in Australia. 
DOI: https://doi.org/10.47405/mjssh.v6i10.1078

\begin{tabular}{lll}
\hline Vaccine hesitancy & Vaccination is voluntarily based. & Implementation of policies \\
& To curb the issue of anti-vaccine & known as "No Jab, No Pay" and \\
groups, there is a proposal for the & "No Jab, No Play" to eradicate \\
& implementation of mandatory & the problem of vaccine \\
immunization programs. & hesitancy.
\end{tabular}

Access to vaccination

Legislation relating COVID-19 Vaccination

As a non-producer of vaccines, action has been taken to secure an agreement to ensure a sufficient supply of vaccines to all populations.

Poisons Act 1952 (Act 366) and its regulations

Sale of Drugs Act 1952 (Act 368) and its regulations

Drugs and Cosmetic Control Gene Technology Act 2001 Regulations 1984

Infectious Disease Prevention and Control Act (Act 342)
Manufacturer of vaccine nevertheless to cater for all population has secured agreement for the supply of the vaccine.

Therapeutic Goods Act of 1989

Therapeutic Goods Regulations 1990
Implementation of policies
known as "No Jab, No Pay" and
"No Jab, No Play" to eradicate
the problem of vaccine
hesitancy. 
about unprecedented events. In keeping up with the spread and reducing morbidity and mortality, scientific progress needed to be accelerated to accommodate the development of vaccines at a speedier rate compared to the pre-COVID-19 era. Because of this, the World Health Organisation (WHO) has issued a master protocol publicly available from early March 2020 as guidance in harmonising COVID-19 clinical trials at the global arena (Davis et al., 2020). Coupled with the advancements in technology, as well as availability of funding and concrete collaboration between vaccine developers and the government (Department of Health, 2021a) the unbelievable speed of vaccine development in the COVID-19 era has been made possible due to the existence of studies and researches over previous comparable pandemics, such as the 2019 H1N1 influenza pandemic, the 2012 Middle East respiratory syndrome (MERS) and the 2003 severe acute respiratory syndrome (SARS) (Davis et al., 2020).

It is worth noting that the unprecedented emergence of COVID-19 viruses has required the standard clinical trial procedure to be revised to cater to the dire needs of such vaccines. In responding to this demand, the government holds the responsibility to allow for expedited procedures of vaccine approval and still assure the safety and efficacy aspect of the vaccine. Instances of this rapid progress of clinical trials are evident in Australia, for example, in the COVID-19 candidate vaccine, V451 trial conducted by the University of Queensland (UQ), working hand in hand with the Commonwealth Serum Laboratories (CSL). Despite the recent launch of its extensive pre-clinical assessment in mid-February 2020, the vaccine trial had then progressed to the first phase of the clinical trials after just five months in July 2020. Compared to the timeline of clinical trials in the pre-COVID-19 era, a significant reduction by at least seven months is seen here (Clinical Trials Arena, 2020). Fast forward to October 2020 , the candidate vaccine had successfully been tested upon one hundred twenty volunteers since the clinical trial inception (Australian Government, n.d.). Regrettably, by December 2020, V451 had to be abandoned as the human immunodeficiency virus (HIV) gp41 protein used in the candidate vaccine produced false-positive HIV antibody test results amongst Phase I participants (Blyth et al., 2021).

Apart from the availability of data collection tools utilised during the previous pandemics, (Davis et al., 2020) as can be seen in the UQ-CSL joint-venture COVID-19 vaccine trial, the clinical trials of COVID-19 vaccines managed to be expedited due to the combination of some of the trial stages so that they overlap between each other, and less time is required to complete the whole clinical trial process. For instance, results will be analysed without waiting for the studies on all participants in each stage to complete in Phase I and II. Instead, upon the availability of data gathered from the first few dozens of participants in Phase I, the research will immediately move on with hundreds more in Phase II. Similarly, clinical trials of Phase III in the COVID-19 era are instantly kicked off upon the availability of the preliminary data from Phase I and II (Department of Health, 2021b). Although the initial rollout of the COVID-19 vaccination is not part of the National Immunisation Program (NIP), the strength of the NIP in delivering a safe, efficient, effective, and transparent vaccination program must still be drawn while allowing a more flexible mechanism in ensuring its delivery promptly (Australian Government, n.d.).

On the other hand, like Malaysia, unlike Australia, which does not develop vaccines, the monitoring of vaccine safety and efficacy should be viewed from a slightly different perspective. In complying with the WHO regulations, each set of vaccines used is required to be checked for compliance. The Ministry of Health $(\mathrm{MOH})$ is responsible to monitor any side effect suffered by a person injected with a vaccine or known as Adverse Events Following Immunisation (AEFI). The Ministry of Health also adopts a strict requirement before accepting the vaccine for the National Immunisation program. The compliance of vaccine makers with Good Manufacturing Practice (GMP) regulations is one of the aspects considered. This is to ensure that the vaccines produced are of high quality and meet industry requirements while minimising any potential dangers throughout the production process. The NPRA's evaluation is based on international regulatory norms and procedures. WHO and the International Council for Harmonisation of Technical Requirements for Pharmaceuticals for Human Use have established international regulatory standards (ICH).

Currently, Malaysia is not involved in COVID-19 vaccine innovation and production. However, Malaysia is urging other vaccine-producing countries to collaborate in developing the COVID-19 vaccine and is willing to provide its facilities, data, and resources to this effort. Once the vaccine is 
available, Malaysia is eager to participate in clinical trials. Because Malaysia is a multi-racial country, it is a good fit for human vaccine studies. Through science diplomacy efforts that were jointly carried out by the Ministry of Health (MOH), Ministry of Foreign Affairs (MFA), and the Ministry of Science, Technology, and Innovation (MOSTI) starting April 2020, the Government has adopted a multipronged approach. This is to enable Malaysia to secure access to a portfolio of COVID-19 vaccines, which is being actively developed worldwide (The Secretariat of the Special Committee for Ensuring Access to Covid-19 Supply (JKJAV, 2021).

The government action in addressing the safety issue of the COVID-19 vaccine can be evidenced in the cases of the AstraZeneca vaccine. In March 2021 there was widespread news in Malaysia claiming the fatal side effect of the AstraZeneca vaccine. The Malaysian Ministry of Health acted fast to investigate and reveal the outcome of the investigation (The Special Committee for Ensuring Access to COVID-19 Vaccine, 2020). It was informed that the AstraZeneca vaccine which the Drug Control Authority has registered is safe to use in the country. The results of the evaluation of the data and the report found that the cases of blood clots were not directly related to the vaccine's side effects. AstraZeneca through a meeting with NPRA informed that as of 8 March 2020 a total of 17 million people has received the vaccine in countries around the European Union (EU). In United Kingdom (UK), out of the vaccine recipients involved, there were 15 cases of blood clots in the veins (Deep Vein Thrombosis syndrome or DVT), while another 22 cases involved blood clots in the pulmonary tract or Pulmonary Embolism. The company has made a detailed assessment of all these cases and concluded that there is no strong evidence to link the COVID-19 AstraZeneca vaccine with the risk of blood clots. The number of blood clotting cases reported is also much lower than the average number of cases expected to occur in that population size (World Health Organisation, 2021).

\section{Registration of new vaccine}

In Australia, the Therapeutic Goods Act of 1989 serves as the foundation for market control, requiring that all medical products imported into, provided in, or exported from Australia be listed with the Australian Register of Therapeutic Goods (ARTG) before they may be supplied in or exported from Australia (Pharmaceuticals Export Promotion Council of India, 2018). Therapeutic goods, as defined by the Therapeutic Goods Act 1989, are goods that can be represented in any form and are used for therapeutic purposes. Generally, therapeutic goods are used to prevent, diagnose, cure or alleviate a disease, ailment, defect, or injury (Therapeutic Goods Administration, 2020). Under the Act, medicines and medical devices are the two primary categories of therapeutic goods. Vaccines are classified under the category of medicines. To be marketed for sale or distribution, all medicines including the Covid19 vaccine must be registered in the ARTG (Kumari et al., 2016).

To allow a greater acceptance towards Covid-19 vaccination, vaccines as therapeutic goods are subjected to a high level of scrutiny and rigorous testing through the licensing and registration requirement under the Act. As such, the Therapeutic Goods Administration (TGA) is designated as the responsible regulatory authority through the said Act and the Therapeutic Goods Regulations 1990. TGA has been tasked to regulate COVID-19 vaccination through licensing of Australian manufacturers and verifying overseas manufacturers' compliance with the same standards as their Australian counterparts (Australian Covid-19 Vaccination Policy, 2020). Before the TGA could approve any license, a strict requirement will have to be adhered to and it is a practice that a vaccine will have to undergo several phases of rigorous clinical trials. Even before these clinical trials, there is a pre-clinical assessment stage whereby laboratory study is conducted before it being extended to animals in ensuring the safety and efficacy of the vaccine against the identified target antigen (National Centre for Immunisation Research and Surveillance, 2020). On the other hand, the Australian Technical Advisory Group on Immunisation (ATAGI) provides technical and clinical advice on vaccines' involvement in the National Immunisation Program and oversees the creation of the Australian Immunisation Handbook. In addition, the Australian Government formed the COVID-19 Vaccine Taskforce in response to the urgent need for action while the COVID-19 Vaccine and Treatments for Australia Science and Industry Technical Advisory Group (SITAG) is advising the government on potential vaccinations especially in the vaccine purchase decision. 


\section{Provisional determination and registration application}

The utmost consideration in registering a vaccine lies in the fact that the benefits outweigh the risk exposed by vaccination (Association of State and Territorial Health Officials, 2020). The safety and timely availability of vaccines is largely attributed to the establishment of TGA in discharging their regulatory duties concerning the registration of vaccines. TGA plays a pivotal role in the initial regulatory approval for the use of COVID-19 vaccines through the provisional determination and registration pathway under the Therapeutic Goods Act of 1989. Section 22C until Section 22F of Therapeutic Goods Act 1989 obliges a pharmaceutical company to observe and comply with provisional determination application requirements. The Act specifies that sponsors must submit a detailed dossier containing information on clinical studies, non-clinical/toxicology investigations, chemistry, manufacturing, risk management, and other information to register a COVID-19 vaccine in Australia. TGA has to analyze the application based on the eligibility requirement and the product's safety, quality, efficacy, and the safety and quality of any new substances in the vaccine before approving it for registration. (Pharmout, 2016). This procedure also entails collecting additional information and clarification from the sponsor and consulting the Advisory Committee on Vaccines (ACV). The ACV was founded by The Australian Government Minister for Health with a special mandate to supplement TGA's expertise and provide aid in registering a vaccine for use and distribution in Australia (Therapeutic Goods Administration (TGA), 2021). The members of the ACV are appointed by the Minister for Health under Regulation 39F of the Therapeutic Goods Regulations 1990 and comprise professionals with distinct medical health experience as well as consumer representatives. To facilitate the process of approving a new vaccine, ACV is required to furnish independent medical advice to the TGA concerning any safety and quality issues. In the event a new vaccine is approved and registered in Australia, prescribers can be comfortable that the TGA has assessed its safety and efficacy with input from the ACV (Vaughan, 1995).

The TGA will run checks on every batch of the vaccines and once it is satisfied with its safety, efficacy, and quality, approval will be granted for its use in Australia. The vaccines will then be provisionally registered in the Australian Register of Therapeutic Goods based on clinical evidence to achieve full registration as quickly as feasible (Department of Health Therapeutic Good Administration, 2021). The approval via the provisional approval pathway for COVID-19 vaccines is valid for an initial duration of two years entitling the pharmaceutical companies to legally supply the vaccines to Australian populations, subject to certain requirements, such as to supply continuous information to TGA on longer-term efficacy and safety based on ongoing clinical trials. This period could be further extended for up to two extensions amounting to a maximum of six years upon the application of the pharmaceutical companies (Therapeutic Goods Administration (TGA), 2021).

Other than the primary legislation governing the registration of the Covid-19 vaccine, the Gene Technology Act 2001 regulates and controls the vaccine with genetically modified organisms (GMOs). Specifically, this Act primarily focused on the protection of health and safety of the people as well as the environment, by recognising and mitigating dangers posed by the gene technology, and by regulating specific dealings with GMOs (Australian Covid-19 Vaccination Policy, 2020). It is important to note that COVID-19 vaccines, such as adenovirus vaccines and some of the mRNA vaccines that use genetically modified organisms (GMOs) will have to undergo an extra layer of robust assessment by the Office of the Gene Technology Regulator (OGTR) for its approval and licensure (Australian Government, n.d.).

In Malaysia, the National Pharmaceutical Regulatory Agency (NPRA) oversees reviewing and registering pharmaceutical (inclusive of vaccine) products. For drug-based products, the Control of Drugs and Cosmetics Regulation 1984 (Revised 2009) (CDCR, 1984) requires all drugs-based products to be registered (CDCR, 1984) before they can be manufactured, sold, supplied, imported, possessed, or administered in Malaysia. The law limits that only local distribution companies can submit a drug-based product registration application. Therefore, foreign companies with no local presence in Malaysia must use a Marketing Authorization Holder (MAH) as their local representative. MAH is responsible for the product application, as well as the quality, safety, and efficacy of the product (Regulation 7(1)(a), CDCR, 1984). 
In June 2014, NPRA in the Drug Evaluation Committee Meeting (no 9/2014) revised the Drug Registration Guidance Documents (DRGD) and inserted an amendment that requires the declaration of source of ingredients that derived from animal origin (active and excipient) including starting materials, gelatine, and the source of capsule shell on immediate container and outer carton labelling of all registered products through the Drug Registration Guidance Document (Drug Evaluation Committee Meeting No 17/2013). Besides the registration, licensing, and labelling requirements, the government also monitors and controls the drug product through batch-marking and product bans. Batch marking is done during the pre-marketing period and functions that also aid in monitoring postmarketing activities. Through batch marking, defective drug products can be traced for recall or disbursement. Product bans on the other hand are a mechanism that involves immediate action of the authority to ban and prohibit the marketing and selling of a drug product that is defective and hazardous (Abdul Aziz, 2017). Premises handling, processing, and sale of drugs are inspected regularly.

\section{Conditional fast-track registration}

The 351st Meeting of the Drug Control Authority on 3 December 2020 agreed to the implementation of conditional fast-track registration for pharmaceutical products during disasters as provided under Regulation 8 of Control of Drug and Cosmetic Regulation (CDCR) 1984 and inserted as an annex under the Guideline on Conditional Registration for New Chemical Entities and Biologics in Malaysia Accordingly, a directive (Directive No. 18 of 2020) has been issued by the Director of Pharmaceutical Services on 15 December 2020 under the provisions of Regulation 29, CDCR 1984 to inform the holder registration in connection with the implementation of conditional fast-track registration for pharmaceutical products during a disaster. This conditional registration mechanism aims to provide immediate access to pharmaceutical products for current treatment or prevention of disaster by using a risk-based approach without ignoring aspects of product quality, safety, and effectiveness.

\section{The Dilemma of Anti-Vaccine Group}

During the COVID-19 crisis, pandemic doubters and those who reject wearing face masks or quarantine have already played a significant role in the pandemic's progression. Different anti-vaccine narratives are being constructed in response to the COVID-19 vaccine, and these narratives are likely to be adopted by huge populations, with serious repercussions. Similarly, both Australia and Malaysia face challenges imposed by the vaccine-hesitant group. Vaccine hesitancy has been highlighted as a major barrier to obtaining COVID-19 herd immunity, and some migrant groups are believed to be among the most vulnerable. Concerning this matter, both governments must understand the factors contributing to hesitancy towards COVID-19 vaccinations to support the initiation of a COVID-19 vaccine program and ensure that communication efforts are targeted to factors impacting acceptability (Seale et al., 2021). In Australia, there was a drastic increase of groups spreading potentially harmful vaccine side effects and conspiracy theories (Wilson, 2021b). Between January 2020 and March 2021, the group's researchers employed CrowdTangle, a social media analysis tool, to track the evolution of 13 public Facebook groups. These organisations ranged in size from major anti-vaccine organisations to minor organisations formed in response to Australia's COVID-19 public health policies. They discovered that throughout that time, the groups rose by 280 percent, to more than 115,000 members (Reset Australia Research Memo, 2021). The most active periods were during lockdowns and the licensing and implementation of the COVID-19 vaccines in Australia.

The Australian government has previously implemented a policy known as "No Jab, No Pay" And “ No Jab, No Play" (Armiento et al., 2020). It means that if the adults do not get vaccinated, they would not be eligible for government assistance, and the children will be restricted from attending kindergartens or childcare centres. This was a response to the report that disclosed that vaccination was not given to over 40,000 Australian children under the age of seven because their parents rejected it (Gelling, 2021). As a result of the "No Jab, No Pay" regulation, many families will be unable to pay their bills (Gelling, 2021). During the spread of COVID-19, the anti-vaccine community has gotten more challenging to approach and has been underestimated. In March 2021, hundreds of people joined 
the "Millions March Against Mandatory Covid Vaccinations" events in Melbourne, Perth, Canberra, and Brisbane (Loomes, 2021). In Australia, nobody is required to have a mandatory vaccine including frontline workers and people who work in aged care.

During the four weeks that the vaccine petition was open, over 300,000 individuals signed it. They claimed that the experimental vaccinations being tested for Covid-19 is going against the Nuremberg Code if made mandatory. This is a misinterpretation of research ethics, which prohibits the use of experimental treatments but not vaccines that have been demonstrated to be safe and effective (Wilson, 2021a).

In Malaysia, one of the thriving challenges to reach herd immunity comes from the anti-vaccine groups. Currently, it is not an offence under the Prevention and Control of Infectious Diseases Act 1988 (Act 342) for individuals who refuse to receive COVID-19 vaccine injections in Malaysia. Vaccine injections through the National Immunisation Programme are made free and voluntarily on listed individuals. However, the Malaysian government is looking to take legal action against antivaccine groups in the country if they are found to be inciting the public from supporting the National COVID-19 Immunisation Program (Berita Harian). The COVID-19 Vaccine Supply Assurance Special Committee is in the process to introduce the implementation of mandatory immunisation programs if the number of registrations fails to reach the group immunity target (Yeoh \& Jua Wen, 2021).

From the legal point of view, there are two discussions on the ability of the government to impose mandatory vaccination. First, looking at the way coronavirus has already reshaped our right to personal liberty, freedom of movement, and assembly that has made way to the right of the Government to impose requirements on its citizens to guarantee rights to life of the majority in the country. On the opposing view, it could be argued that enforcing vaccination amounted to oppression that is against the human rights principle. They argued that the physical nature of a vaccination that is piercing the skin sets it apart from restricting religious, civil, or political rights and even from forcing people to stay indoors or have their fingerprints taken.

\section{Access to vaccination}

The effort has been made by the government to ensure the continuous supply of vaccines to all populations in Australia. Limitation of vaccine supply in Australia and the urgency to reach herd immunity through vaccinations to avoid long-term transmission has led the way to the purchase of vaccines by the Australian Government(MacIntyre et al., 2021). Emphasising the purchasing and manufacturing of vaccines as one of the core measures under Australia's COVID-19 Vaccine and Treatment Strategy, the government secured access to vaccines through direct procurement or manufacturing under license in Australia. The government has made significant gains in purchasing and manufacturing through:

\footnotetext{
i. $\quad$ advance purchase agreements to assure the direct purchase of vaccination;

ii. manufacturing agreements to increase the capability and capacity of Australian manufacturers;

iii. international and multilateral agreements to encourage and ease of access for Australia; and

iv. contracts for the purchase of products, resources, and services required for the distribution and administration of vaccines and treatments.
}

(Australian Government, 2020)

In the context of COVID-19 vaccines purchased for Australia, the government has entered into five separate agreements for the supply of COVID-19 vaccinations provided they are found to be safe and effective by the TGA (Department of Health, 2021b). For instance, Australia purchased the Novavax vaccine amounting to 40 million doses which will be delivered to Australia from foreign countries in the first half of 2021. Before a vaccine is accepted to be purchased by the government, all vaccines are 
required to pass different stages of research trials, rigorous assessment, and approval processes to prove the safety, quality, and efficacy of the vaccine. Concerning this matter, the approval obtained by Pfizer COVID-19 vaccines is subject to certain strict conditions, such as the need for Pfizer to continue providing data to the TGA on longer-term efficacy and safety from ongoing clinical trials and postmarket assessment (Department of Health Australian Government, 2021). It is also pertinent to note that unlawful imports of COVID-19 vaccine are regularly monitored as the TGA is working closely with Australian Border Force (ABF) and importers are subject to legal action in the event of any unapproved vaccines being imported to Australia (Therapeutic Goods Administration, 2021).

Apart from the purchase of vaccines, the Australian government had manufactured the vaccines in the country. For instance, the Australian biopharmaceutical company, CSL plans to manufacture 30 million doses of the University of Oxford vaccine or commonly known as AstraZeneca vaccine in Australia while another 3.8 million doses of AstraZeneca vaccine has been delivered to Australia from overseas in early 2021 manner (Australian Government, n.d.). On the other hand, international effort is apparent when the media reported that in September 2021, the governments of the United Kingdom and Australia will share COVID-19 vaccine doses to benefit each country's vaccination programme. The United Kingdom will send 4 million Pfizer/BioNTech vaccines to Australia to boost the Australian vaccination programme (Emily, 2021).

On the issue of access to vaccination, the Malaysian government targeted 150,000 to 160,000 COVID19 vaccine deliveries by the middle of 2021 (Phase 3) when more supplies are received and more Vaccination Centers (PPVs) are opened. Procurement is carried out centrally at the MOH and direct deliveries are made to listed government facilities. Guaranteed access to the COVID-19 vaccine is through:

i. Direct negotiation with the Product Registration Holder company/Vaccine Manufacturers/ Vaccine Distributors.

ii. Direct negotiations through COVAX Facility.

iii. Negotiations continue through bilateral agreements between the two countries (G2G).

The first agreement was entered with COVAX Facility through an Optional Purchase Arrangement signed on 23 November 2020 that guarantees a supply of vaccines to 10 percent of the country's population, while the second agreement was an initial purchase agreement with pharmaceutical company Pfizer signed on 24 November the same year to secure a supply of vaccines for 20 percent of the country population (12.8 million doses) (Bernama, 2021b). The COVAX facility is a multi-pronged strategy approach that will enable countries to diversify their options as well as reduce the risk of focusing on only bilateral efforts to procure COVID-19 vaccines. The Government of Malaysia has also signed a cooperation agreement for the development and access to vaccines with the People's Republic of China on 18 November 2020 as an effort to secure access to vaccination for the people. This agreement constitutes a platform to give Malaysia priority in gaining access to COVID-19 vaccines produced by the People's Republic of China. The international strategic cooperation whether multilateral or bilateral is Malaysia's step in supporting national aspirations and businesses' global solidarity towards combating COVID-19. It helps in diversifying vaccine procurement options for the country and reduces dependence on a single source only.

The Malaysian Government has later signed the Terms Sheet document together with Pharmaniaga Lifescience Sdn Bhd and Solution Biologics Sdn Bhd to manufacture COVID-19 vaccine by fill and finish, which is the final filling process vaccine into vials before it is distributed. Through this step, the Sinovac vaccine and CanSinoBio are purchased in bulk and the manufacturing process is then implemented in Malaysia which in turn accelerates the adoption of vaccines. On top of that, the government negotiated with the Russian government for research and development (R\&D) purposes, as well as production of Sputnik V vaccine in Malaysia to increase the total dose of COVID-19 vaccines that can be used in Malaysia and the region. 


\section{Conclusion}

The study critically discusses the issues relating to vaccination activities that were based on past experiences and the current health crisis. Where many countries had experience battling pandemics that can spare some assistance in facing the current spread of COVID-19, but still due to some unique characteristics of the new attack, governments of the world need to devise their conventional way to eradicate the attack of the unseen virus. Discussion includes the adequacy of current law that sufficiently monitors the safety and efficacy of the newly created COVID-19 vaccine; the approved emergency expedited clinical trial for COVID-19 vaccine product, the scope of power of the Drug Control Authority, assuring access to vaccine and the risk posed by the vaccine-hesitant group. The findings can be summarised that governments of both countries unanimously have great concern over safety and efficacy issues relating to the newly invented vaccine. This concern is planted by the shortened period of clinical trial and the uncertain guarantee of immunology impact on the vaccinated people. Nevertheless, due to the desperate need, these countries have taken progressive actions to monitor and control any unprecedented outcome of the vaccination program. This study forwarded suggestions that may assist in addressing the issue of safety and efficacy of the COVID-19 vaccine product and the improvement on control and monitoring mechanisms that can be learned from both countries. Future research should delve into the issue of immunology of the COVID-19 vaccine in eradicating the pandemic.

\section{References}

Abdul Aziz, N. (2017). The Need for Legal and Administrative Framework for Halal Pharmaceutical in Malaysia. https://doi.org/10.1016/j.sbspro.2014.01.1114

Armiento, R., Hoq, M., Kua, E., Crawford, N., Perrett, K. P., Elia, S., \& Danchin, M. (2020). Impact of Australian mandatory 'No Jab, No Pay and 'No Jab, No Play' immunisation policies on immunisation services, parental attitudes to vaccination, and vaccine uptake, in a tertiary pediatric hospital, the Royal Children's Hospital, Melbourne. Vaccine, 38(33), 5231-5240. https://doi.org/10.1016/j.vaccine.2020.05.094

Association of State and Territorial Health Officials. (2020). COVID-19 Vaccine Approval Process. Department of Health Therapeutic Goods Administration. https://www.state.nj.us/health/cd/documents/topics/NCOV/vaccine_approval_process_astho.pdf

Australian Government. (n.d.). Australia COVID-19 Vaccination Policy.

Australian Government. (2020). Australia's Covid-19 Vaccine and Treatment. https://www.health.gov.au/resources/publications/australias-covid-19-vaccine-and-treatmentstrategy

Berita Harian. (, June). Kerajaan kaji tindakan undang-undang kepada golongan antivaksin. BH Online. https://www.bharian.com.my/berita/nasional/2021/06/824179/kerajaan-kaji-tindakanundang-undang-kepada-golongan-antivaksin

Bernama. (2021a). AstraZeneca COVID-19 Vaccine Safe for Use in Malaysia - Dr. Adham. https://www.bernama.com/en/news.php?id=1945100

Bernama. (2021b). Isu pembekalan vaksin COVID-19 syarikat Pfizer tak jejas bekalan untuk Malaysia - Khairy. Astroawani. https://www.astroawani.com/berita-malaysia/isu-pembekalan-vaksincovid19-syarikat-pfizer-tak-jejas-bekalan-untuk-malaysia-khairy-272033

Blyth, C. C., Flanagan, K. L., Gibbs, R. A., Crawford, N. W., \& Cheng, A. C. (2021). Key steps in Our Journey to a COVID-19 Vaccine Program. Medical Journal of Australia, 214(6), 249-251.e1. https://doi.org/10.5694/mja2.50978

Borriello, A., Master, D., Pellegrini, A., \& Rose, J. M. (2021). Preferences for a COVID-19 Vaccine in Australia. Vaccine, 39(3), 473-479. https://doi.org/10.1016/j.vaccine.2020.12.032

Clinical Trials Arena. (2020). Australia's Queensland University begins the Covid-19 vaccine trial. Clinical Trials Arena.

Davis, J., Ferreira, D., Denholm, J. T., \& Tong, S. Y. (2020). Clinical trials for the prevention and treatment of coronavirus disease 2019 (COVID-19): The current state of play | The Medical Journal of Australia. The Medical Journal of Australia.

Department of Health. (2021a). COVID-19 vaccines | Australian Government Department of Health. 
Department of Health. (2021b). How COVID-19 vaccines are tested and approved | Australian Government Department of Health.

$\begin{array}{llll}\text { Australian Covid-19 Vaccination } & \text { Policy, }\end{array}$ https://www.health.gov.au/resources/publications/covid-19-vaccination-australian-covid-19vaccination-policy

Department of Health Australian Government. (2021). Australia's s Vaccine Agreements. https://www.health.gov.au/initiatives-and-programs/covid-19-vaccines/covid-19-vaccinegovernment-response/australias-vaccine-agreements

Department of Health Therapeutic Good Administration. (2021). Vaccines overview 14. https://www.tga.gov.au/vaccines-overview

Deplanque, D., \& Launay, O. (2021). Efficacy of COVID-19 vaccines: From clinical trials to real life. Therapies, 76(4), 277-283. https://doi.org/10.1016/j.therap.2021.05.004

Emily, H. (2021). Vaccine Doses to Enhance Rollout of Life -. https://www.newsmedical.net/news/20210903/UK-and-Australia-will-share-COVID-19-vaccine-doses-to-enhancerollout-of-life-saving-jabs.aspx

Gelling, P. (2021). Australia imposes penalties on anti-vaxxers. The World. https://www.pri.org/stories/australia-imposes-penalties-anti-vaxxers.

Joslyn Panting, A., Mohd Zin, Z., Jaafar, N., Perialathan, K., Shafizal Sheikh Ilman, S., Ridwan Zakaria, M., \& Author, C. (2018). Potential Factors Contributing to Vaccine Hesitancy among Parents in Malaysia: An Overview. International Journal of Health Sciences \& Research (Www.Ijhsr.Org), 8(7), 360. www.ijhsr.org

Kashte, S., Gulbake, A., El-Amin, S. F., \& Gupta, A. (2021). COVID-19 Vaccines: Rapid Development, Implications, Challenges, and Future Prospects. Human Cell, 34(3), 711-733. https://doi.org/10.1007/s13577-021-00512-4

Kaur, R. J., Dutta, S., Bhardwaj, P., Charan, J., Dhingra, S., Mitra, P., Singh, K., Yadav, D., Sharma, P., \& Misra, S. (2021). Adverse Events Reported From COVID-19 Vaccine Trials: A Systematic Review. Indian Journal of Clinical Biochemistry. https://doi.org/10.1007/s12291-021-00968-z

Khoo, Y. S. K., Ghani, A. A., Navamukundan, A. A., Jahis, R., \& Gamil, A. (2020). Unique product quality considerations in vaccine development, registration, and new program implementation in Malaysia. Human Vaccines and Immunotherapeutics, 16(3), 530-538. https://doi.org/10.1080/21645515.2019.1667206

Kumari, B. S., G.Sai, H., M.V., Nagabhushanam D.Nagarjuna, R., \& Brahmaiah, B. (2016). Current Regulatory Requirements for Registration of Medicines, Compilation, and Submission of Dossier in Australian Therapeutic Goods Administration. International Journal of Advanced Scientific and Technical Research, 6(6), 144-157.

Kuok, Y. C., \& Wong, T. (2021). Guide on Covid-19 Vaccination: Regulatory Issues. Rajah \& Tann Asia. https://www.christopherleeong.com/media/4389/2021_05_covid-19_vaccines.pdf

Lisa, L. M., \& David Kelen, G. (2021). Is the COVID-19 Vaccine Safe? https://www.hopkinsmedicine.org/health/conditions-and-diseases/coronavirus/is-the-covid19vaccine-safe

Loomes, P. (2021). Coronavirus vaccine: What we misunderstand about anti-vaxxers. News.Com.Au. https://www.news.com.au/lifestyle/health/health-problems/coronavirus-vaccine-what-wemisunderstand-about-antivaxxers/news-story/0ef947d1e56e560ee835a0f043f23a33.

MacIntyre, C. R., Costantino, V., \& Trent, M. (2021). Modeling of COVID-19 vaccination strategies and herd immunity, in scenarios of limited and full vaccine supply in NSW, Australia. Vaccine, XXXX, 0-7. https://doi.org/10.1016/j.vaccine.2021.04.042

Mukherjee, R. (2020). Global efforts on vaccines for COVID-19: Since, sooner or later, we all will catch the coronavirus. Journal of Biosciences, 45, 1-10. https://doi.org/10.1007/s12038-02000040-7

National Centre for Immunisation Research and Surveillance. (2020). Phases of clinical trials | NCIRS.

Panting, A., Mohd Zin, Z., Jaafar, N., Perialathan, K., Sheikh Ilman, S. S., \& Zakaria, M. R. (2020). Potential Factors Contributing to Vaccine Hesitancy among Parents in Malaysia: An Overview. International Journal of Health Science and Research, 8(July 2018), 360-365.

Pharmaceuticals Export Promotion Council of India. (2018). Regulatory \& Market Profile of Australia. In Pharmexcil. 
Pharmout. (2016). White Paper: How to List or Register a Medicine in Australia (pp. 1-17). www.pharmout.net

Ramli, M. A., Suet Yan, D. S., \& Lim, M. H. (2020). Combating Covid-19: Legal Requirement and Procedures for the Importation of Vaccine into Malaysia. Azmi \& Associates. https://amcham.com.my/wp-content/uploads/Article-20200402-Combating-COVID-19-LegalRequirements-and-Procedures-for-the-Importation-of-Vaccine-into-Malaysia.pdf

Reset Australia Research Memo. (2021). Anti-vaccination \& Vaccine Hesitant Narratives Intensify in Australian Facebook Groups. https://au.reset.tech/uploads/resetaustralia_sociallistening_report_100521-1.pdf

Rumetta, J., Abdul-Hadi, H., \& Lee, Y. K. (2020). A Qualitative Study on Parents' Reasons and Recommendations for Childhood Vaccination Refusal in Malaysia. Journal of Infection and Public Health, 13(2), 199-203. https://doi.org/10.1016/j.jiph.2019.07.027

Seale, H., Heywood, A. E., Leask, J., Sheel, M., Durrheim, D. N., Bolsewicz, K., \& Kaur, R. (2021). Examining Australian Public Perceptions and Behaviors towards a Future COVID-19 Vaccine. BMC Infectious Diseases, 21(1), 1-9. https://doi.org/10.1186/s12879-021-05833-1

Sharun, K., \& Dhama, K. (2021). COVID-19 Vaccine Diplomacy and Equitable Access to Vaccines Amid Ongoing Pandemic. Archives of Medical Research, XXXX, 19-21. https://doi.org/10.1016/j.arcmed.2021.04.006

Silva, J., Bratberg, J., \& Lemay, V. (2021). COVID-19 and Influenza Vaccine Hesitancy among College Students. Journal of the American Pharmacists Association. https://doi.org/10.1016/j.japh.2021.05.009

The Secretariat of the Special Committee for Ensuring Access to Covid-19 Supply (JKJAV). (2021). National Covid-19 Immunisation Programme (Issue February). https://www.vaksincovid.gov.my/pdf/National_COVID-19_Immunisation_Programme.pdf

The Special Committee for Ensuring Access to COVID-19 Vaccine. (2020). AstraZeneca COVID-19 Vaccine (AZD1222).

Therapeutic Goods Administration. (2020). What are "therapeutic goods"? Department of Health Therapeutic Goods Administration. http://www.tga.gov.au/what-are-therapeutic-goods

Therapeutic Goods Administration. (2021). COVID-19 vaccine advertising and import compliance. Department of Health. https://www.tga.gov.au/covid-19-vaccine-advertising-and-importcompliance

Therapeutic Goods Administration (TGA). (2021). Advisory Committee on Vaccines (ACV). Australian Government Department of Health Therapeutic Goods Administration. https://www.tga.gov.au/committee/advisory-committee-vaccines-acv

Vaughan, G. (1995). The Australian Drug Regulatory System. Australian Prescriber, NPS Medicinewise, 3 July. https://doi.org/10.18773/austprescr.1995.068

Wan Abhar, W. N. A. (2021). Safety Updates on COVID-19 Vaccine (Comirnaty®). National Pharmaceutical Regulatory Agency (NPRA). https://www.hsa.gov.sg/COVID19-vaccines-safetyupdates

Wan Taib, W. R., Mohd Yusoff, N. A., Raja Hussin, T. M. A., \& Ahmad, A. (2017). Issues in Vaccine Hesitancy in Malaysia. J. of Biomed. \& Clin. Sci, 2(June), 42-46.

Wilson, C. (2021a). Anti-vaxxers are flooding Parliament with petitions about vaccines. MSN News. https://www.msn.com/en-au/news/australia/anti-vaxxers-are-flooding-parliament-with-petitionsabout-vaccines/ar-AANdz9o

Wilson, C. (2021b). Australians are embracing anti-vaccine Facebook groups filled with conspiracy theories and lies. MSN News. https://www.msn.com/en-au/news/australia/australians-areembracing-anti-vaccine-facebook-groups-filled-with-conspiracy-theories-and-lies/ar-BB1gQwJH.

Wong, Y. J., \& Lee, S. W. H. (2021). COVID-19: A call for awareness or mandatory vaccination even in pandemics? Journal of Global Health, 11, 2019-2021. https://doi.org/10.7189/jogh.11.03005

World Health Organisation. (2021). Statement for healthcare professionals: How COVID-19 vaccines are regulated for safety and effectiveness: Joint Statement from the International Coalition of Medicines Regulatory Authorities and World Health Organisation. 1-11. https://www.who.int/news/item/11-06-2021-statement-for-healthcare-professionals-how-covid19-vaccines-are-regulated-for-safety-and-effectiveness

Yeoh, L., \& Jua Wen, P. (2021). Mandatory Covid-19 Vaccination To Reach Herd Immunity in 
Malaysian Journal of Social Sciences and Humanities (MJSSH), Volume 6, Issue 10, (page 319 - 333), 2021

DOI: https://doi.org/10.47405/mjssh.v6i10.1078

Malaysia. Lexology. https://www.lexology.com/library/detail.aspx?g=e0e7ae2d-3cff-4d8b-9f7b3f43e19037f9 